\title{
Predicting the density of structural timber members in service. The combine use of wood cores and drill resistance data
}

\author{
M.J. Morales-Conde $\bowtie$, C. Rodríguez-Liñán ${ }^{\mathrm{a}}$, J. Saporiti-Machado ${ }^{\mathrm{b}}$ \\ a. Universidad de Sevilla (Sevilla, Spain) \\ b. Laboratório Nacional de Engenharia Civil (Lisboa, Portugal) \\ \mmorales@us.es
}

\author{
Received 7 May 2013 \\ Accepted 8 October 2013 \\ Available on line 20 August 2014
}

\begin{abstract}
Drilling devices is used to get information about the cross-section properties and internal defects of structural members. Drill resistance is correlated with density which is often used to predict the mechanical properties of timber elements. However in situ a regression curve cannot be obtained and pre-existent curves provides unreliable predictions. The present paper proposes a procedure for in situ "calibration" of drill resistance data. The "calibration" is based on density values from wood cores taken in the close vicinity of drill holes. Two approaches were tested. One approach based on a regression curve built using wood cores density and drill resistance values obtained from a limited number of members. The other approach uses the information of one wood core to "calibrate" the drill resistance profile taken at the same member. Following this procedure a density prediction is obtained showing a low mean percentage error and a medium coefficient of determination.
\end{abstract}

KEYWORDS: Timber; Density; Resistograh; Wood core; Structures in service; Mechanical Properties

Citation / Citar como: Morales-Conde, M.J.; Rodríguez-Liñán, C.; Saporiti-Machado, J. (2014) Predicting the density of structural timber members in service. The combine use of wood cores and drill resistance data. Mater. Construcc. 64 [315], e029 http://dx.doi.org/10.3989/mc.2014.03113.

RESUMEN: Predicción de la densidad de elementos estructurales de madera en servicio mediante el uso combinado de pequeñas probetas y datos de resistencia a la perforación. Los dispositivos de perforación se utilizan a menudo para obtener información sobre las propiedades de la sección transversal y defectos internos de los elementos estructurales de madera. La resistencia a la perforación se correlaciona con la densidad que, a menudo, se utiliza para obtener la predicción de las propiedades mecánicas de los elementos de madera. Sin embargo, una curva de regresión no puede ser obtenida in situ y las curvas de preexistentes proporcionan predicciones poco fiables. En el presente trabajo se propone un procedimiento de "calibración" in situ de los datos de resistencia de perforación obtenidos en cada caso. La "calibración" se basa en los valores de densidad de pequeñas probetas de madera tomadas en las inmediaciones de los taladros. Para ello se plantean 2 métodos: Un primer enfoque basado en obtener una curva de regresión a partir de los valores de densidad de pequeñas probetas de madera y los valores de resistencia a la perforación obtenidos de un número limitado de elementos de madera. El otro enfoque pretende utilizar la información de una pequeña probeta madera para "calibrar" un perfil de resistencia completo tomado del mismo elemento. Siguiendo este procedimiento se obtiene una densidad de predicción que muestra un error de porcentaje medio bajo $(-0,31 \%)$ y un coeficiente de determinación medio $\left(\mathrm{r}^{2}=0,53\right)$.

PALABRAS CLAVE: Madera; Densidad; Resistógrafo; Pequeña probeta; Estructuras en servicio; Propiedades Mecánicas

Copyright: (C) 2014 CSIC. This is an open-access article distributed under the terms of the Creative Commons Attribution-Non Commercial (by-nc) Spain 3.0 License. 


\section{INTRODUCTION}

Wood as an organic material is vulnerable to attack of biotic agents, such as fungi or insects, and abiotic agents, such as fire. These vulnerabilities lead frequently to the rejection of wood as a structural material.

However, in recent years issues as sustainability and preservation of our historic heritage provide support for the development of procedures that could ensure the integrity of existent timber structures. The preservation of historic timber structures is only possible if reliable non-destructive (NDE) or semi-destructive (SDE) evaluation methods are available. The application of these methods provides information on the mechanical performance and conservation (deterioration level) of members and joints. This information is crucial to ensure a reliable assessment of the safety and serviceability level of the structure. Only then efficient repair or strengthening solutions can be proposed.

This assessment requires the existence of information on the reference properties of timber members: bending strength; stiffness; and, density. It is clear that, although it would be the most accurate method, this information cannot be obtained from destructive tests since these ones would lead to the loss of structural integrity (1).

Density is probably the best single criterion of strength (2). It is used for selection of trees at the stand as well as for grading timber according with their end-uses as it is positively correlated with the mechanical properties of timber (strength and stiffness). Coefficients of determination between 31.86 and 37.22 for bending strength and 45.13 and 29.78 for modulus of elasticity were obtained for maritime pine timber specimens from the Atlantic and Mediterranean areas, respectively (3).

The non-destructive evaluation of density is usually carried out by: application of visual strength grading standards rules (only for softwoods); extraction of wood core samples; and, resistance drilling tests. In the last decades several NDE methods have been developed (4) being drilling resistance one the most used semi-destructive techniques in the evaluation of timber structural elements. This technique is classified as a Local Test Methods (LTM). This classification corresponds to the volume of material under test (5). Usually LTM provide information about localized areas (examined sections) and support other more global inspection methods, such as ultrasonic or vibration techniques.

The objective of the present paper is to discuss the possibility of improving the capacity of the drill resistance technique to predict the density of timber elements in situ by means of wood core density data. Drill resistance equipments has the capability of analysing the full cross section of structural timber members while performing a meaningful hole $(\varnothing=3 \mathrm{~mm})$. Whereas wood cores allows a direct reading of the density but performs a hole with some impact $(\varnothing \geq 6 \mathrm{~mm})$ and often it is not possible to analyse the full cross section. However wood cores provide a direct reading of density whereas drill resistance does not. Therefore the combination of these two techniques can provide a better prediction of the wood density of the element. For the purpose of testing this hypothesis Pinus spp. roundwood timber elements removed from service during a rehabilitation work was used. The procedures tested are described in the following section. The choice of Pinus spp. wood as a case study responds to its common presence in many Portuguese and Spanish historical buildings.

\section{BACKGROUND IN THE USE OF DRILL RESISTANCE FOR ASSESSING TIMBER ELEMENTS IN SITU}

Drill resistance measures the torque applied to the needle in order to maintain a constant penetration velocity into the wood piece. Density variations in the wood material will correspond to variations of the torque production and result in a resistance drill profile along the depth of the wood element.

The available equipments produce a very small drill hole (diameter between 1.5 and $3 \mathrm{~mm}$ ) in wood. This damage does not affect the structural behaviour of timber members. Drill resistance technique is generally used to: assess the presence and extension of biological deterioration, mainly decay (6); to predict the density profile (2); and, the strength of clear wood (7).

Recently two publications identify some limitations of this technique $(8,9)$, Table 1 .

Table 2 shows a summary of the applications of drilling resistance (using equipments similar to the one used in the present paper) in the assessment of structural timber members. The data presented does not intend to cover all the works carried out but only to show the variability of results obtained.

The data presented in Table 2 shows clearly that different test methods could lead to significant changes in the efficiency of the regression curves. The range of correlation coefficients $(0.21$ to 0.69$)$ for density mentioned in Table 2 is similar to that mentioned by (8). These differences can be related with different wood species, different conditioning conditions (variations of moisture content), different equipments (or models), different operating parameters (drill velocity and drill direction in relation with the growth rings) or simply the way the drill is made and how carefully the operation is conducted. Therefore the possibility of extrapolating existent regression curves to new situations is highly doubtful. 
TABLE 1. Limitations regarding drill resistance reported by two recent state of the art reports on non and semi-destructive techniques

\begin{tabular}{l}
\hline Lear et al. (2010) \\
\hline Access problems: limit space to operate the equipment; obstruction from other structural members; \\
site conditions (height and orientation of the drill along with the heavy weight of the equipment). \\
Local evaluation: often requires that multiple drills should be made which turns it time consuming \\
and implies a higher level of damage.
\end{tabular}

Damage: a small hole is made in the material which turn this method a semi-destructive or lowdestructive one. However, sometimes given the historical importance of the object or member even a small hole is not allowed.

Interaction with wood material: problems of deviation of the drill (low stiffness) cause by wood anatomical structure.

Representativeness: Not applicable to the evaluation of wood's features.

Maintenance: Requires a careful attention to the condition of the needle tip.

Extrapolation to wood composites: Given the composition of glued laminated timber the technique is less accurate than for solid timber

TABLE 2. Review of some results (coefficients of determination) from the application of drilling resistance to predict physical and mechanical properties of wood since 2000

\begin{tabular}{lcc}
\hline References & Density & Compression parallel to fibers \\
\hline$(10)$ & 0.67 & 0.05 \\
$(11)$ & 0.09 to 0.61 & - \\
$(12)$ & 0.58 & - \\
$(13)$ & $0.40 ; 0.19$ & $0.08 ; 0.11$ \\
$(14)$ & 0.90 & - \\
$(15)$ & 0.21 to 0.69 & - \\
$(5)$ & 0.38 (old wood $>150$ year in service) 0.36 (new & - \\
$(16)$ & wood) & 0.70 \\
$(7)$ & 0.004 & 0.24 \\
$(17)$ & 0.87 & 0.05 to 0.70 \\
Range of values: & - & \\
\hline
\end{tabular}

\section{DESCRIPTION OF THE PROPOSED METHOD}

How to predict density from drill resistance profiles is one of the problems regarding its application to timber member in-service. The use of preexisting regression curves is unreliable as already stated. For this reason a new procedure was tested. The hypothesis was to use density data obtain from wood cores to "calibrate" the drill resistance profiles.

The proposed method is based on the extraction of a limited number of small-diameter wood cores $(\varnothing=7 \mathrm{~mm})$. This extraction is made in the close vicinity of drilling holes. Density of wood cores is then compared with drill resistance values. Two approaches of the method are compared in this paper, one using a group-based prediction and the other using an individual-based prediction.

Group-based prediction comprises the collection of data (drilling resistance profiles and wood cores) from a limit number of timber members. The regression curve is then used to support the density predictions for other timber members. In these last members only the drilling resistance test is made.

Individual-based prediction comprises the use the density of a wood core to "calibrate" the drill resistance profile obtained in the same timber element. 
This procedure begins by accepting that the $R M$ (resistographic measure) value corresponding to the first $20 \mathrm{~mm}$ exterior layer of wood $\left(R M_{20}\right)$ to be equal to the density obtained from the wood core with $20 \mathrm{~mm}$ length. Using this data the following $R M$ values of the graph are transformed into density values.

These two approaches has as advantages to turn possible: to adjust the parameters of the equipment to the situation found in the structure (wood species and moisture content); and to use the equipment in a particular structure as part of a standalone method.

\section{EXPERIMENTAL PROCEDURE}

\subsection{Timber specimens}

Fifty pine (Pinus spp.) wood piles were obtained from the foundation of an old building located in Lisbon's downtown. The building was erected in the XVIII century, after the Great Earthquake in 1755. Therefore the wood piles analysed were in service for more than 200 years. The wood piles were use in the foundations during Lisbon's reconstruction with the intention to stiffen the alluvial soil and to create a working platform above the water level (18). Also pine timber species are the most common wood source used in historical buildings in Spain and Portugal.

The wood piles used show on average a diameter between 100 to $200 \mathrm{~mm}$, Fig. 1 .

The wood piles were air dried until their moisture content was below $18 \%$. For some specimens it was necessary to provide an artificial drying cycle inside a climatic chamber.

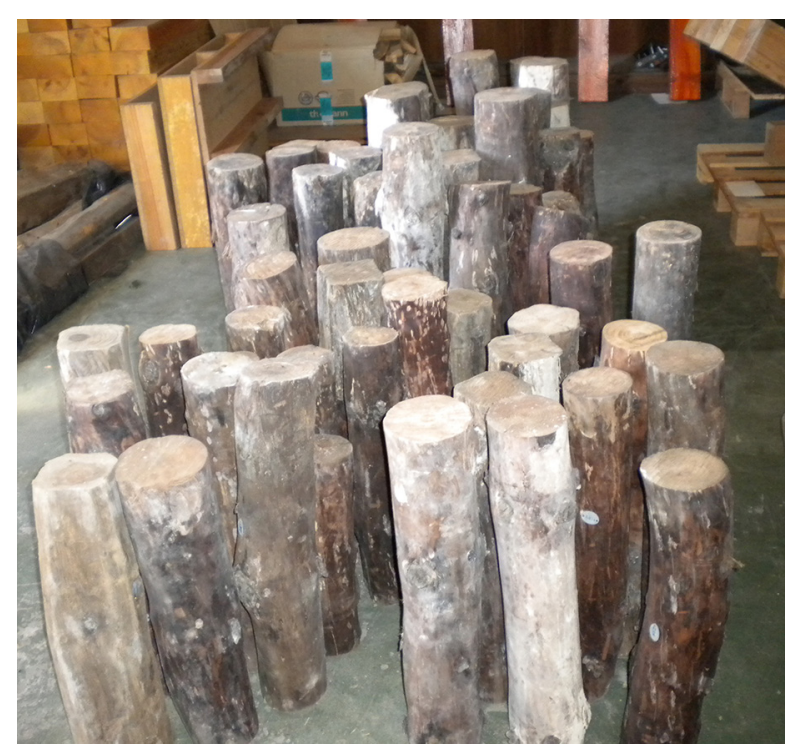

FIGURE 1. Specimens used in the experimental procedure.

\subsection{Testing}

\subsubsection{Drill resistance tests}

The drill equipment IML Resi-B 1280 was used in the present study. The equipment consists of a $1.5 \mathrm{~mm}$ diameter drill needle that can penetrate inside wood up to $280 \mathrm{~mm}$. This equipment has seven advance speed stages (from $60 \mathrm{~mm} / \mathrm{min}$ to $500 \mathrm{~mm} / \mathrm{min}$ ). The resistance to drilling is concentrated at the tip of the needle that shows a diameter twice as large as the needle's shaft, thus reducing lateral friction between the shaft and the walls of the wood hole.

In the present study two orthogonal drill holes (A and $\mathrm{B})$ were made in the radial direction of a wood section free of defects (Fig. 2).

For the study the equipment was set to a constant speed of $150 \mathrm{~mm} / \mathrm{min}$ and the resistance to drill was recorded at every $0.04 \mathrm{~mm}$ of depth. The information obtained during the tests was stored in the device and transfer to Excel to be analysed.

A drill resistance profile was obtained from each drill (Fig. 3). The so-called resistographic measure $(R M)$ was calculated (5) considering the full depth of the wood pile and/or only the first $20 \mathrm{~mm}$.

The resistographic measure (RM) was obtained by dividing the full area defined by the drill resistance profile into $n$ sectors defined by a drill depth of $0.04 \mathrm{~mm}$. The $R M$ was obtained as follows [eq. 1]:

$$
R M_{1, \mathrm{j}}=\frac{\sum_{i=1}^{n} \text { Area }_{i}}{l}
$$

$R M_{1, \mathrm{j}}$ represents the $R M$ reading considering a drilling depth equal to $l$ (full or $20 \mathrm{~mm}$ ) done at the location $j(j=\mathrm{A}$ or $j=\mathrm{B})$. The area of the sector $i$ of

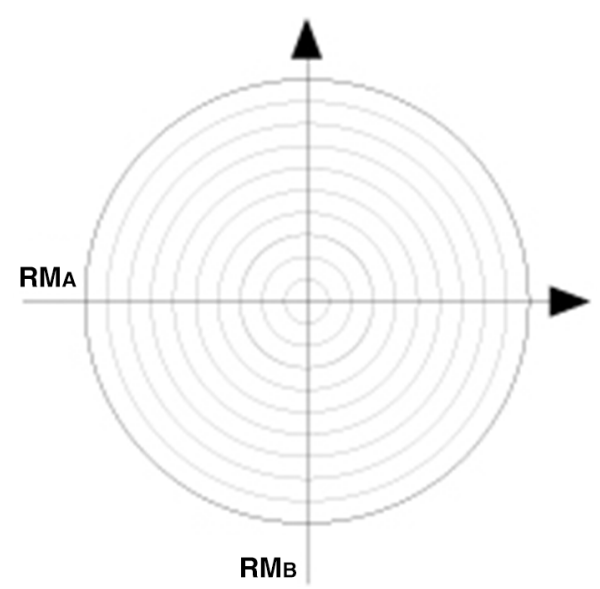

FIGURE 2. Schematic representation of the two perpendicular Resistograph measurements made in each wood pile. 


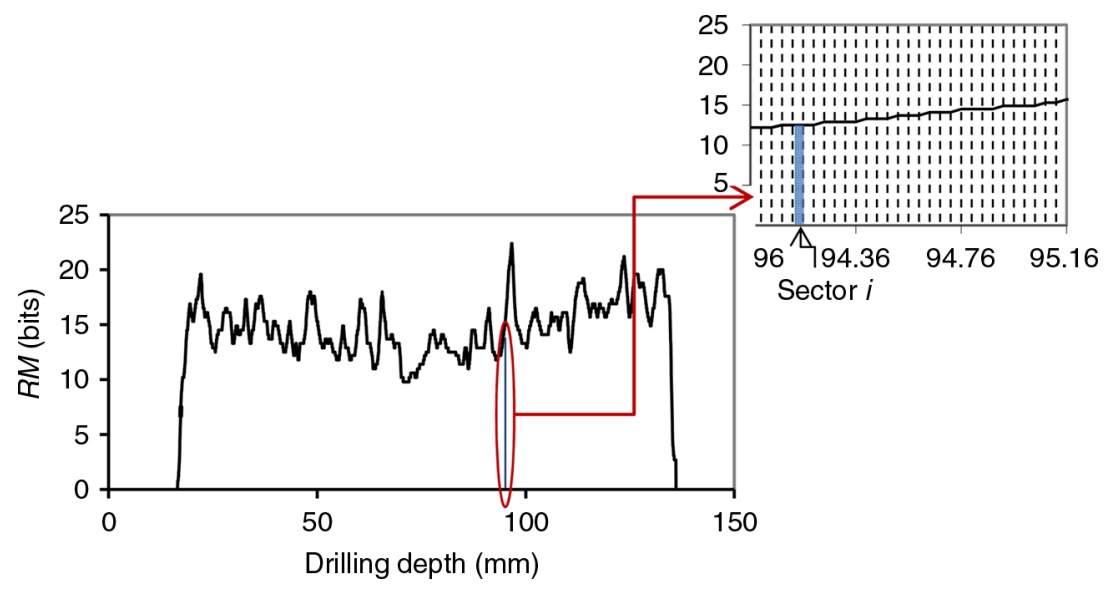

FiguRE 3. Example of Resistograph profile obtained.

the profile $\left(\right.$ Area $\left._{i}\right)$ was obtained using the trapezoid rule (area equal to the average drilling resistance of sector $i$ divided by drill depth of each sector, in this case $0.04 \mathrm{~mm}$ ), Fig. 3.

It was decided not to make any correction for moisture content to $R M$ values. This decision was taken since the effect of moisture content in $R M$ values found for maritime pine was not significant (19). The study included wood samples conditioned for two moisture content levels $(12 \%$ and $18 \%)$ and two different velocities $(70 \mathrm{~mm} / \mathrm{min}$ and 140 $\mathrm{mm} / \mathrm{min}$ ). These levels embrace the range of moisture content values of the wood disks (13\% to $18 \%$ ). This same result (no significant influence of moisture content) was also reported by (20).

\subsubsection{Density and moisture content}

After making the drill resistance test, from each pile it was cut a 3 to $4 \mathrm{~cm}$ thick disc. The disk was cut in order to enclose the drill holes (Fig. 4). In each piece a wood core was obtained close to the location of drill A.

The wood cores $(\varnothing 7 \mathrm{~mm})$ were obtained using a dry wood borer from RINNTECH ${ }^{\circledR}$ near the

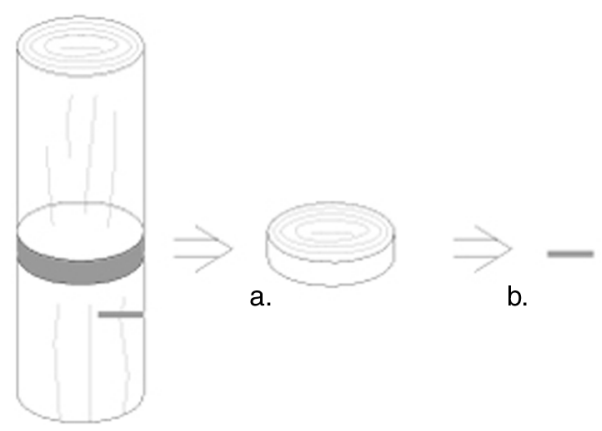

Figure 4 . a) 3 to $4 \mathrm{~cm}$ thick discs free of defects enclose drill holes; b) Wood cores extracted close to the location of drill A. drill hole A. The cores were cut to obtain a common length of $20 \mathrm{~mm}$. The cross-section dimensions and weight of the cores were determined.

The determination of the density of the disks $\left(\rho_{\text {disk }}\right)$ was based on the ratio mass over volume at a particular moisture content value. The density of the wood slices was determined according to test method B, mode III, described in ASTM D2395-07a (21). The volume was measured using an electronic balance of capacity of $30 \mathrm{~kg}$ and $1 \mathrm{~g}$ precision using Archimedes' principle.

The density of the wood cores was determined according with test method E, increment cores, described in ASTM D2395-07a (21). The dimensions (diameter and length) were determined by a calliper with an accuracy of $0.01 \mathrm{~mm}$.

The mass of the disks and cores was measured by using a digital balance with an accuracy of $0.01 \mathrm{~g}$.

Moisture content was determined according with EN 13183-1 (22). The wood specimens were dried in an oven at constant temperature $\left(103 \pm 2{ }^{\circ} \mathrm{C}\right)$. The tests specimens were considered dried when the density variation was smaller than $0.1 \%$ in a period of 2 hours, as recommended by the standard.

The density of wood cores was not corrected for moisture content. This decision had in mind the purpose of the study to correlate the density of wood cores with the drill profile at in situ conditions (including moisture content). Therefore both wood cores and drill resistance values were compared under the same conditions. In Table 3 it is shown the moisture content of wood disks and wood cores.

TABLE 3. Moisture content of wood disks and wood cores

\begin{tabular}{rlcc}
\hline & & Wood disks & Wood cores \\
\hline Moisture & Mean (\%) & 15.78 & 15.03 \\
content & Coef. Variation (\%) & 6.18 & 5.75 \\
\hline
\end{tabular}




\subsection{Data analysis}

Regression analysis was carried out using Excel. The bias of the estimation provided by the regression curves was evaluated through the mean percentage error (MPE) as follows [eq. 2]:

$$
M P E=\frac{1}{N} \sum_{i=1}^{N} \frac{y_{i}-\hat{y}_{i}}{y_{i}} 100
$$

Where $N$ represents the number of observations, $y_{i}$ is the value of the $i^{\text {th }}$ observed dependent variable and $\bar{y}_{i}$ is the value of the predicted $i^{\text {th }}$ dependent variable.

For estimating the global performance of the regression a jackknife or "leave one out" procedure was applied. This procedure is used as a crossvalidation of the regression curve. In the present case, given the number of observations, 50 iterations (partial regressions) were performed. In each iteration one observation $(i)$ was left-out and a jackknife regression curve acquired as:

$y_{\text {jack },-i}=a_{-i}+b_{-i} x_{-i}$

Where $y_{\text {jack,-i }}$ is the predicted independent variable given the partial estimate of parameters of the regression curve obtained leaving out the $i^{\text {th }}$ observation.

In each jackknife iteration a partial coefficient of determination $\left(r_{j a c k,-i}^{2}\right)$ was determined. Also the average of those coefficients was determined $\left(\bar{r}_{j a c k}^{2}\right)$.

To evaluate the sensibility of the regression curve to the number of wood core extracted a bootstrap method was applied.

The bootstrap method consisted in considering nine different sample sizes $(n)$ for the regression analysis $(n=5,10,15,20,25,30,35,40,45)$. For testing each sample size one hundred simulations (regression analysis) were performed.

The jackknife and bootstrap methods were carried out using the Software R version 2.13.1 (23).

The coefficients of determination were classify following the principle adopted in the JCSS Probabilistic Code (24): $0.8 \leq|\mathrm{r}|$ high; $0.6 \leq|\mathrm{r}|<0.8$ medium; $0.4 \leq|\mathrm{r}|<0.6$ low; $0.2 \leq|\mathrm{r}|<0.4$ very low; $|\mathrm{r}|<0.2$ no correlation.

\section{RESULTS AND DISCUSSION}

\subsection{Classical approach}

The drill resistance equipment capability to predict the density of a piece of wood is usually assessed by regression analysis. Figure. 5 shows the scatter graphs obtained in the present study between density of the wood disk cut from the piles and resistographic measurement $\left(R M_{\text {full,A\&B }}=\right.$ average of $R M_{\mathrm{A}}$ and $R M_{\mathrm{B}}$ ). The regression curve obtained has a coefficient of determination equal to $r^{2}=0.70$.
This result is slightly weaker than the values obtained in previous studies for clear wood maritime pine (Pinus pinaster Ait.): $r^{2}=0.76$ (11); and $r^{2}=0.87$ (7). In these studies it was used the same equipment but a different penetration velocity (150 and $70 \mathrm{~mm} / \mathrm{min}$, respectively). These values showed the variability that can be expected when using drill resistance as independent variable to obtain a prediction of a timber element density. The results mentioned above are well within the mid-range of values found in literature, Table 2.

In situ drill resistance as density predictor is generally based on data from removed timber members (25). This procedure generally cannot be used in practice. One possible approach is to predict new values by using regression curves obtained from previous studies.

However the question about how to validate these predictions is still open.

Comparing the regression curves obtained in the present study and the one from a previous study (7), Fig. 6, a significant difference was found. The two studies used the same wood species and equipment but a different penetration velocity. In case the equation presented by (7) should have been used a significant higher average error $(M P E=-24.89 \%)$ would be achieved when compared with the average error obtained in the present study $(M P E=0.21 \%)$.

A possible effect of time in service was not taken into account since available studies do not show any influence of this variable $(5,7)$.

The result presented stresses the dependence of drill resistance results on the type of equipment used and operating conditions. Therefore the applicability of existent regression curves (even if determined using the same wood species and equipment) is compromised. At least if a validation of these curves using data from in situ tests are not carried out.

\subsection{Proposed approach}

Given the previous conclusion a novel procedure is proposed. This procedure consists of using wood cores as "calibration" data for the drill resistance data. Both wood cores and drill resistance should be taken in the same volume of material.

As explained before (section 3) two different approaches were tested. One related with a general evaluation of a large number of structural timber members (group-based prediction). The other concerns the evaluation of a particular structural timber member (individual-based prediction).

\subsubsection{Group-based prediction}

A first step concerns the ability of wood cores to represent the density of wood disks. Figure 7 shows the correlation obtained in the present study 
a)

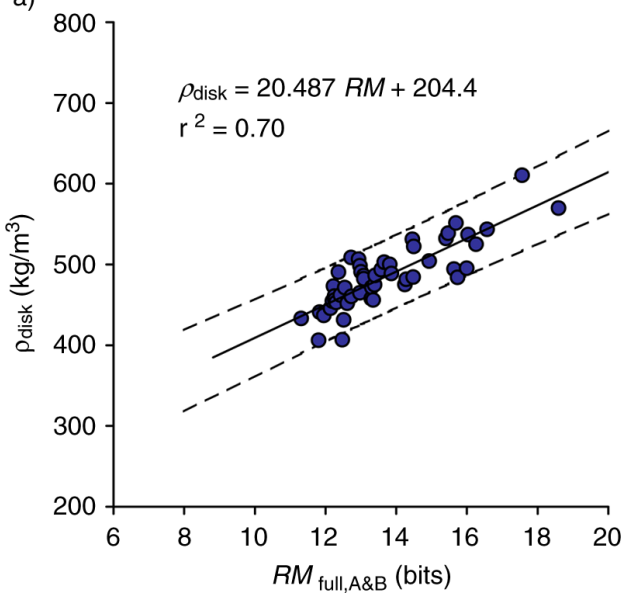

b)

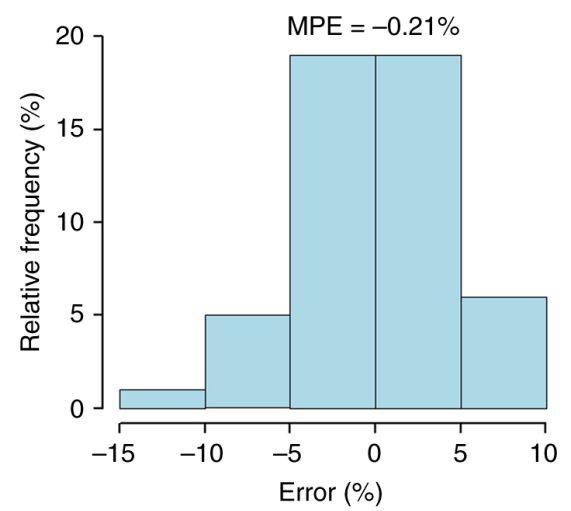

FIGURE 5. Density versus resistographic measurement $\left(R M_{\text {full,A\&B }}\right)$ for wood disks: a) regression curve and $95 \%$ confidence intervals for the predictions; b) histogram of errors.

between density values obtained from wood cores (depth around $20 \mathrm{~mm}$ ) and wood disks.

The correlation achieved is clearly inferior to the one obtained for the drilling resistance, Fig. 5. This result was expected since wood cores in this study only represent the first $20 \mathrm{~mm}$ of the cross-section whereas the drilling profile represents the full cross-section. A similar result to Fig. 7 was obtained when comparing the full drill profile $\left(R M_{\text {full,A\&B }}\right)$ with the profile corresponding to the first $20 \mathrm{~mm}\left(R M_{20, \mathrm{~A} \& \mathrm{~B}}\right)$, Fig. 8 .

When using the RM regarding the first $20 \mathrm{~mm}$ drilling $\left(R M_{20}\right)$ to predict the density of a core matching the same $20 \mathrm{~mm}$ a significant improvement of the coefficient of determination was obtained, $r^{2}=0.73$, Fig. 9. This coefficient is similar to the one obtained in Fig. 5. Likewise this regression curve provides a small bias $(M P E=0.17 \%)$ as indicated in

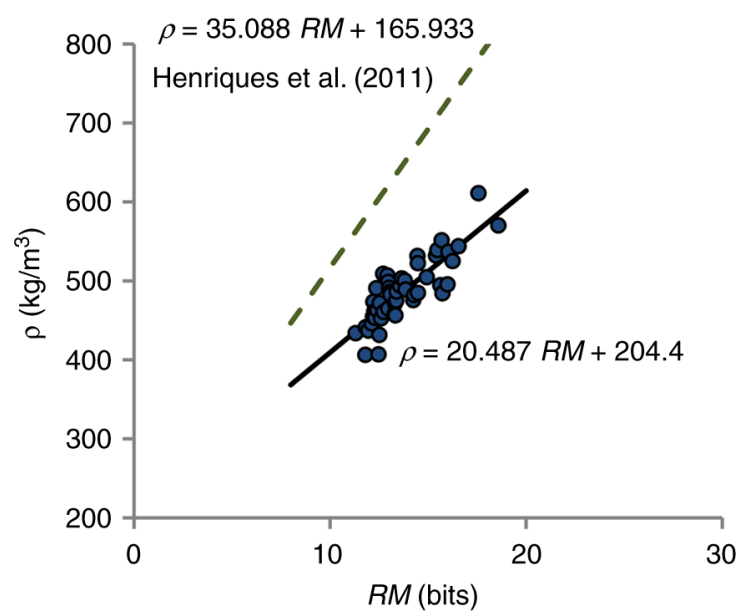

FIGURE 6. Comparison between the application of Henriques et al. (2011) expression and the expression calculated in this study for the $R M_{\text {full,A\&B }}$ values obtained for the wood disks.
Fig. 9b. The results show a good agreement between $R M$ and wood core's density values.

For assessing the robustness of the coefficient of determination it was conducted a jackknife procedure. An average $\bar{r}_{\text {jack }}^{2}=0.73$ was obtained showing an average $M P E$ of $0.19 \%$. Figure 10a shows the histogram with the spread of the partial estimates of the coefficient of determination.

The bias (measured by $M P E$ ) represented in Figure $10 \mathrm{~b}$, considering all the prediction errors of the 50 partial regression curves is comparable with the initial bias (considering all 50 experimental results), Fig. 9b. This result shows the robustness of the test results. As indicated in Fig. 9 a high correlation and a low mean error is associated with the regression curve for a sample of 50 wood cores.

These results indicate the possibility of obtaining in situ a regression curve from wood cores taken in vicinity of drill holes. New drill resistance tests can then be directly related to density values.

However, the number of wood cores possible to be extracted during an inspection to a timber structure is in large situations restricted, namely due to preservation of historical heritage and economic reasons.

In order to assess the robustness of the regression given different sample size a bootstrapping method was applied.

Figure 11 shows the result of applying the bootstrapping method (see Section 4.3) to evaluate the accuracy of the assessment of the coefficient of determination as function of the number of wood cores used for establishing the regression curve.

As expected as the number of wood cores used in the regression increases (sample size) the higher is the robustness of the coefficient of determination possible to be obtained. In the present case it is considered the minimum sample size as 20 in order 
a)

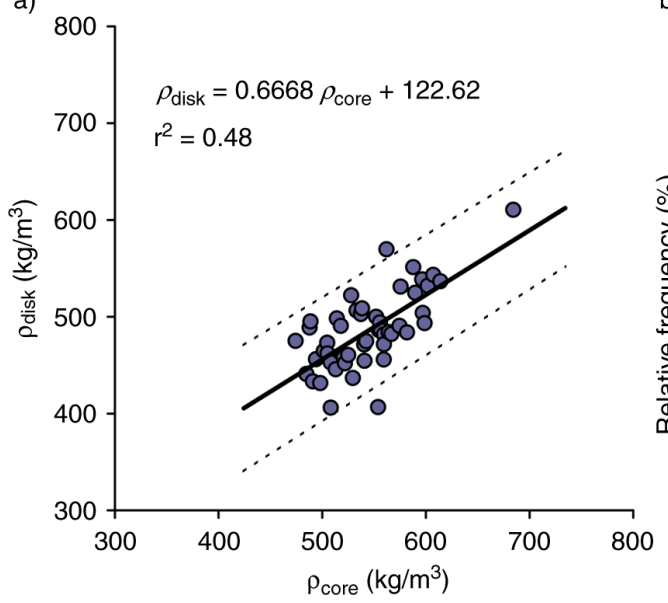

b)

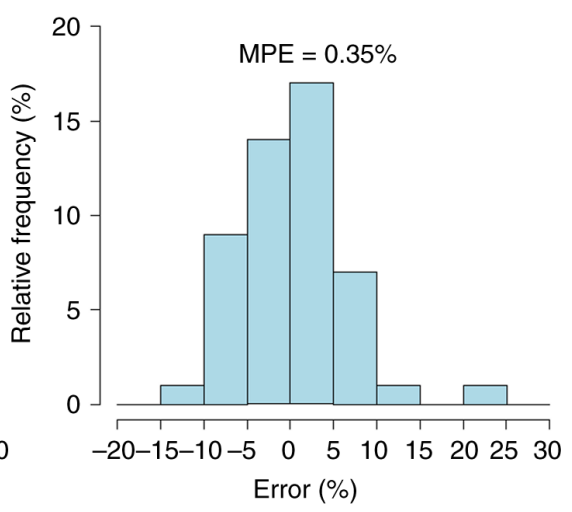

FIGURE 7. a) Correlation between density values obtained from wood cores and density values provided from experimental tests over wood disks - regression curve and 95\% intervals for predictions; b) histogram of errors.

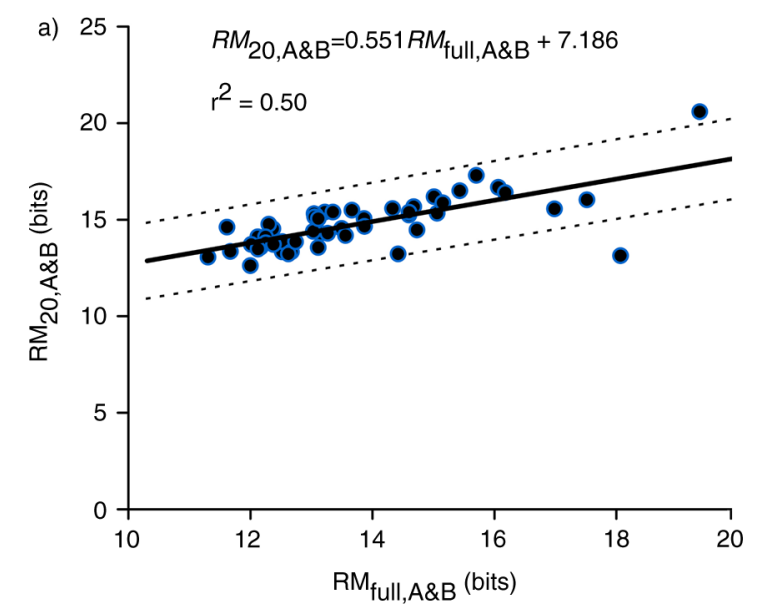

b)

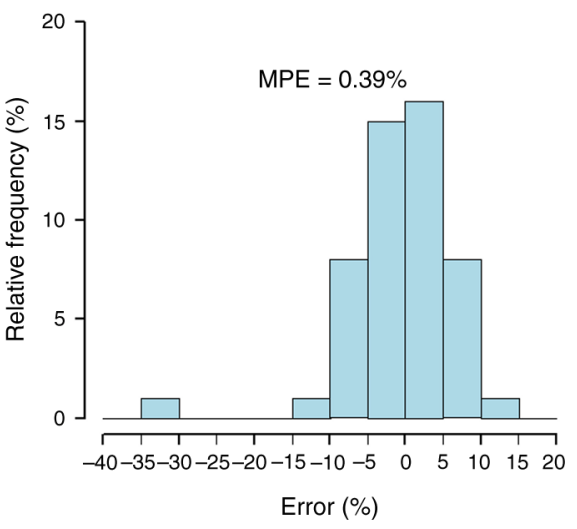

Figure 8. a) Correlation between the Resistograph Measure (RM) corresponding to he full profile and only to the first $20 \mathrm{~mm}$ - regression curve and $95 \%$ intervals for predictions; b) histogram of errors.
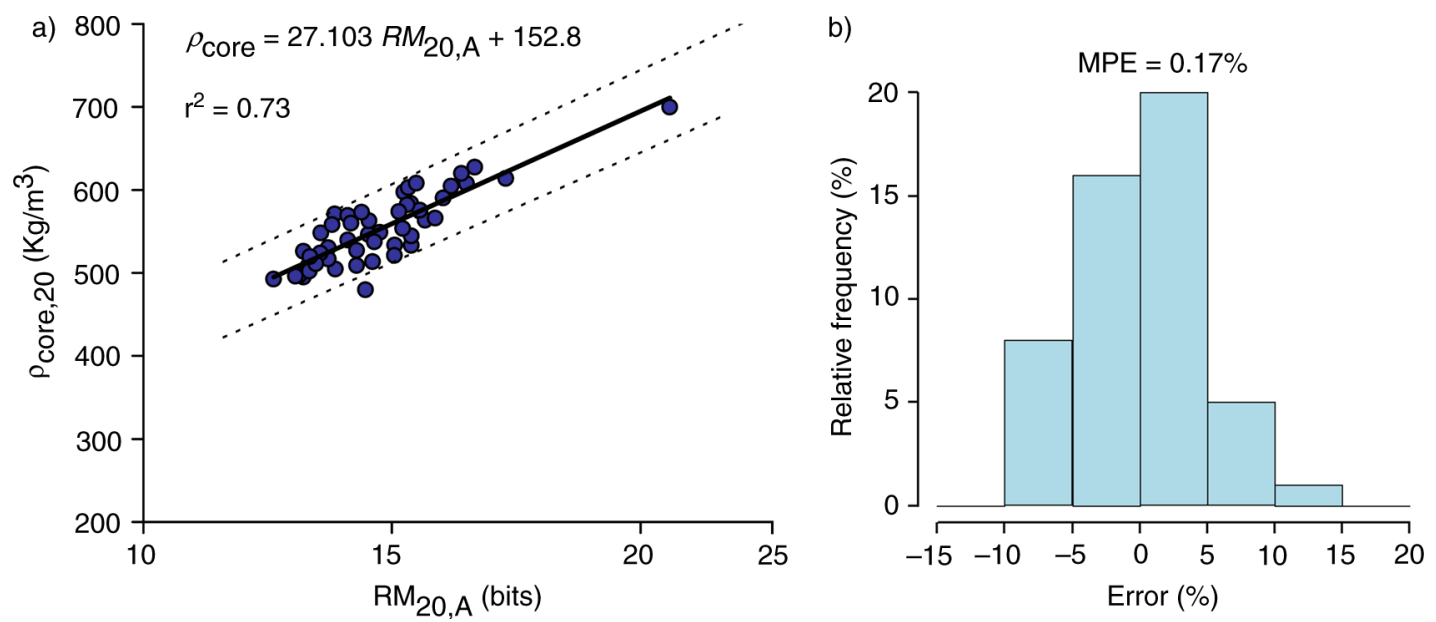

Figure 9. a) Correlation between the Resistograph Measure $\left(R M_{20}\right)$ and density of wood cores ( $\rho$ core)- regression curve and $95 \%$ intervals for predictions; b) histogram of errors. 

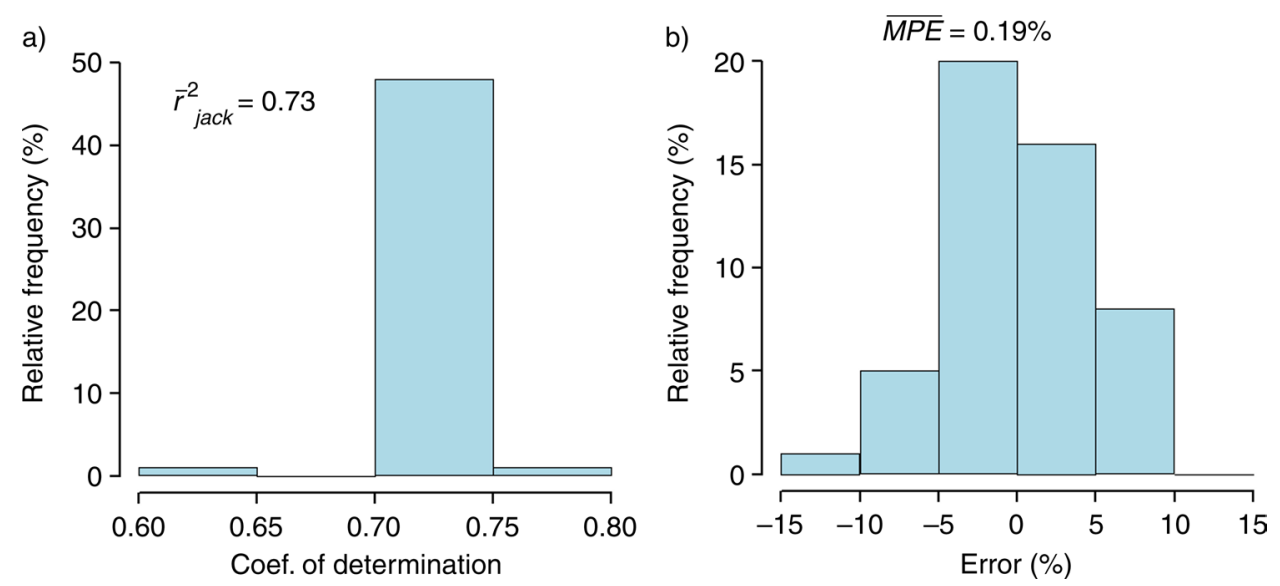

FIGURE 10. a) Histogram with the spread of the partial estimates of the coefficient of determination; b) corresponding MPE to the 50 partial regression curves.

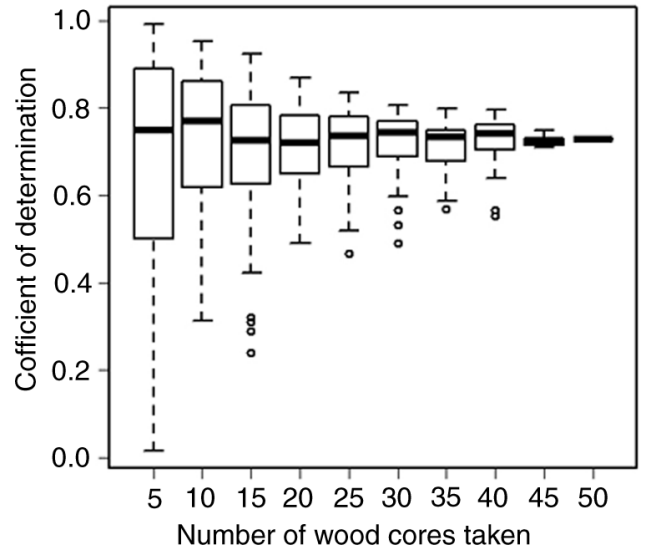

FIGURE 11. Coefficients of determination as function of the number of wood cores taken as independent variables (circles outlier values, values below or above the lower or upper quartile, respectively, plus 1.5 times the length of the interquartile range).

to get a reliable regression curve (with at least a coefficient of determination above 0.4 - medium correlation according with the criterion given in Section 4.3).

\subsubsection{Individual-based prediction}

In this case it was tested the possibility of using the density of a wood core with a length of around $20 \mathrm{~mm}$, to "calibrate" the drilling resistance profile. Both wood core and drill resistance were carried out as close as possible of each other. The objective was to transform the drill profile in a density profile Fig. 12 via an Excel application.

Figure 13 shows the relation between the predicted density calibrating the profiles obtained by means of the wood core extracted and the real density of the wood disks ( $\left.\rho_{\text {drill,core }}\right)$.

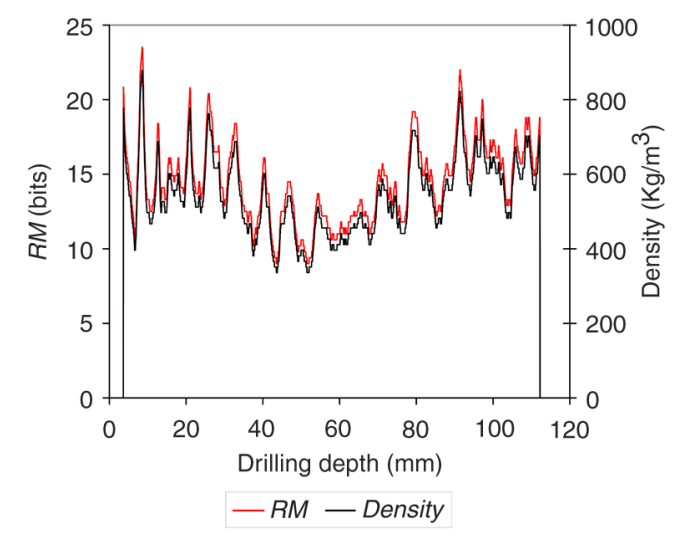

FIGURE 12. Conversion of drill resistance profile into density profile using the relation $R M_{20}=\rho$ core.

The coefficient of determination $\left(r^{2}=0.53\right)$ is higher than the one obtained for the correlation between the wood core density and the density of the disk $\left(r^{2}=0.48\right.$, Fig. 7a). This approach showed a slight improvement of the capacity for predicting density.

The mean percentage error of the prediction also decreases slightly from 0.35 (Fig. 7b) to -0.31 (Fig. 13b).

\section{CONCLUSIONS}

A procedure is presented to improve in situ prediction of timber member's density using drill resistance testing. Wood cores are used for obtaining a direct reading of the density of the superficial layers of timber members (first $20 \mathrm{~mm}$ ). This information is then used to "calibrate" drill resistance data following two different approaches: a group; and, an individual-based prediction. The group approach showed a high correlation $\left(r^{2}=0.73\right)$ between the 

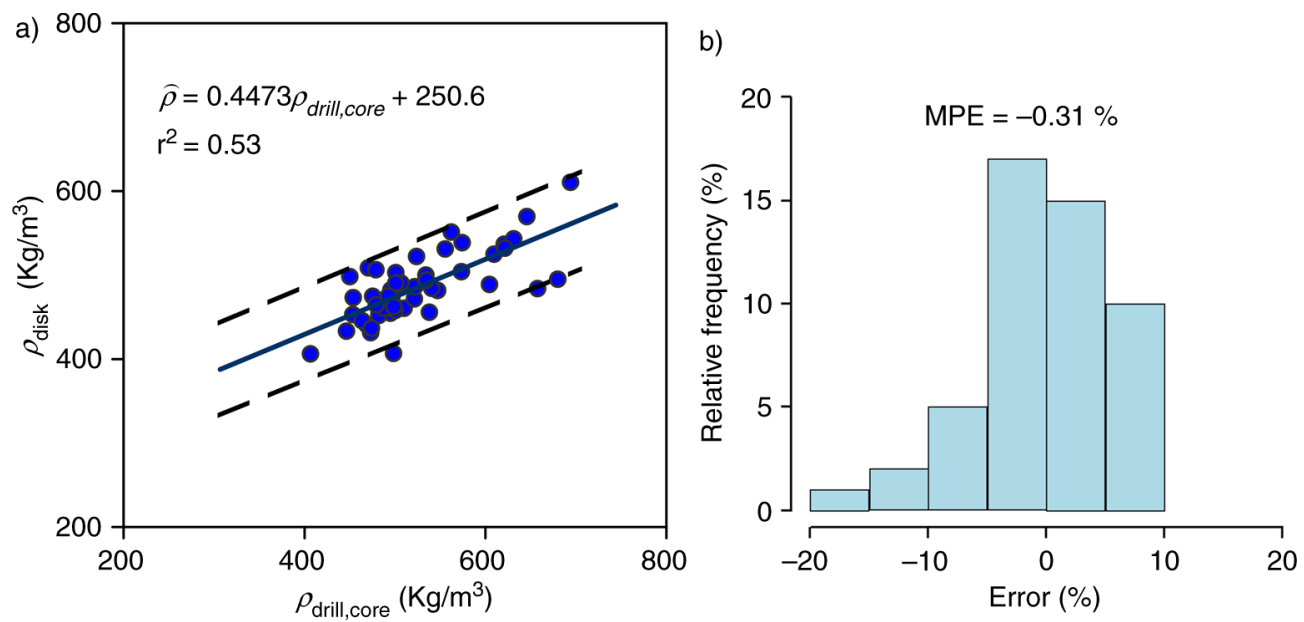

FIGURE 13. Density of the wood disks vs. predicted density (mean value of the density profile).

resistographic measure and wood cores both measured over the same wood volume (external timber $20 \mathrm{~mm}$ layer). However timber's cross section variation of density compromises the capability to predict with the same accuracy the global density (medium correlation $-r^{2}=0.48$ )

For the assessment of an individual timber member an individual-based prediction was tested. The density of the wood core was first used to calibrate the drill resistance profile corresponding to the first $20 \mathrm{~mm}$ of the cross section. Afterwards the drill resistance was transformed into a density profile and a mean density value obtained. The results showed that the use of these mean values (taken from density profiles) resulted in an increase of the correlation with the density of wood disks. Although the good adjustment between drill resistance profiles and density profiles (Fig. 12), the increase of the accuracy when compared with the straight use of density from wood cores is not significant $\left(r^{2}=0.48\right.$ $\rightarrow r^{2}=0.53$ ).

The methods proposed (group and individualbased predictions) provide procedures that can be used to "calibrate" the drill resistance data and obtain predictions of density. However the methods showed a significant room for improvements if considered: the high correlation $\left(r^{2}=0.70\right)$ obtained between resistographic measure $(R M)$ and wood disk's density; and, the high correlation $\left(r^{2}=0.73\right)$ between wood core's density and resistographic measure measured in the same wood volume $(20 \mathrm{~mm})$.

\section{ACKNOWLEDGMENTS}

This study was partially supported by the Fundação para a Ciência e a Tecnologia (FCT) through the research project PTDC/ECM/099833/ 2008.

\section{REFERENCES}

1. Calderoni, C.; De Matteis, G.; Giubileo, C.; Mazzolani, F.M. (2009). Experimental correlations between destructive and non-destructive tests on ancient timber elements. Engineering Structures, 32[2], 442-448. http://dx.doi.org/ 10.1016/j.engstruct.2009.10.006.

2. Rinn, F.; Schweingruber, F-H.; Schär, E. (1996) Resistograph and X-ray density charts of wood. Comparative evaluation of drill resistance profiles and X-ray density charts for different wood species. Holzforschung, 50[4], 303-311. http:// dx.doi.org/10.1515/hfsg.1996.50.4.303.

3. Fernadez-Golfin Seco, J.I.; Barra, M.R.D. (1996) Growth rate as predictor of density and mechanical quality of sawn timber from fast growing species. Holz als Roh-und Werkstoff, 54, 171-174. http://dx.doi.org/10.1007/s001070050161.

4. Kasal, B.; Tannert, T. (Editors) (2011) In-situ assessment of timber. RILEM State of the Art Reports, Vol. 7. Springer Verlag.

5. Lourenço, P.; Feio, A.; Machado, J.S. (2007) Chestnut wood in compression perpendicular to the grain: Non-destructive correlations for test results in new and old wood. Construc. Build. Mat. 21, 1617-1627. http://dx.doi.org/10.1016/j. conbuildmat.2006.07.011.

6. Brashaw, B.; Vatalaro, R.; Ross, R.J.; Wang, X.; Schmieding, S.; Okstad, W. (2011) Historic log cabin structural condition assessment and rehabilitation - A case study. In: Ferenc Divos (ed) $17^{\text {th }}$ International Nondestructive Testing and Evaluation of Wood Symposium, 505-512.

7. Henriques, D.; Nunes, L.; Machado, J.S.; Brito, J. (2011) Timber in Buildings: Estimation of Some Properties using Pilodyn and Resistograph. Procc. International Conference on Durability of Building Materials and Components. Porto, Portugal.

8. Lear, G.; Kasal, B.; Anthony, R. (2010) Resistance drilling. Bohumil Kasal and Thomas Tannert (Eds) In: In situ Assessment of Structural Timber. RILEM State of the Art Reports. Springer, 51-57.

9. Tannert, T. (2010) Drill resistance. Phillip Dietsch and Jochen Köhler (Eds) In: Assessment of timber structures. COST E 55 report. Shaker Verlag, 72-74.

10. Ceraldi, C.; Mormone, V.; Russo-Ermolli, E. (2001) Resistographic inspection of ancient timber structures for the evaluation of mechanical characteristics. Materials and Structures, 34, 59-64. http://dx.doi.org/10.1007/BF02482201.

11. Gantz, C.H. (2002) Evaluating the efficiency of the Resistograph to estimate genetic parameters for wood density in two softwood and two hardwood species. Master's Thesis, Faculty of North Carolina State University. 
12. Lin, C.J.; Wang, S.Y.; Lin, F.C.; Chiu, C.M. (2003) Effect of moisture content on the drill resistance value in taiwania plantation wood. Wood and Fiber Science, 35, 234-238.

13. Tseng, Y.J.; Hsu, M.F. (2008) Evaluating the Mechanical Properties of Wooden Components Using Drill Resistance Method. Procc $10^{\text {th }}$ World Conference on Timber Engineering, 303-310. Singapore.

14. Lee Jun-Jae (2004) Reliability analysis of deteriorated post member. Procc $8^{\text {th }}$ World Conference on Timber Engineering, 223-228.

15. Kasal, B.; Anthony, R.W. (2004) Advances in in situ evaluation of timber structures. Progress in Structural Engineering and Materials, 6, 94-103. http://dx.doi.org/10.1002/pse.170.

16. Piazza, M.; Riggio, M. (2008) Visual strength-grading and NDT of timber in traditional structures. Journal of Building Appraisal, 3, 267-296. http://dx.doi.org/10.1057/jba.2008.4.

17. Zhang, H.; Wang, X.; Zhu, L.; Ross, R.J.; Brashaw, B.K. (2011) An integrated NDT approach for determinaning residual strength of ancient wood structural members. $17^{\text {th }}$ International Nondestructive Testing and Evaluation of Wood Symposium, 547-554. Ferenc Divos (ed).

18. Ramos, L.; Lourenço, P.B. (2004) Modeling and vulnerability of historical city centers in seismic areas: a case study in Lisbon. Engineering Structures, 26, 1295-1310. http:// dx.doi.org/10.1016/j.engstruct.2004.04.008.

19. Machado, J.S.; Cruz, H. (1997) Assessment of timber structures. Determination of density profile by non-destructive methods. Revista Portuguesa de Engenharia de Estruturas $42,15-18$.

20. Johnstone, D.; Tausz, M.; Moore, G.; Nicolas, M. (2010) Quantifying wood decay in Sidney bluegum (Eucalyptus saligna) trees. Arboriculture \& Urban Forestry 36 [6], 243-252.

21. ASTM standard D2395-07a (2007) Standard Test Methods for Specific Gravity of Wood and Wood-Based Materials. ASTM International, West Conshohocken.

22. EN 13183-1:2002. (2002) Contenido de humedad de una pieza de madera aserrada- Parte1: Determinación por el método de secado en estufa.

23. R version 2.13.1 (2011) The R Foundation for Statistical Computing JCSS Probabilistic Code.

24. Grippa, M.R.; Faggiano, B.; Marzo, A.; Mazzolani, F.M. (2010) Combined methods for in situ mechanical identification of ancient timber structures based on non-destructive tests. $11^{\text {th }}$ World Conference on Timber Engineering. Ario Ceccotti and Jan-Willem van de Kuilen (Eds). 